\title{
ANNA JUSTINA FERREIRA NERY: UM MARCO NA HISTÓRIADA ENFERMAGEM BRASILEIRA
}

\author{
ANNA JUSTINAFERREIRANERY: AMYTH INTHE HISTORY OF THE \\ BRAZILIAN NURSING \\ ANNA JUSTINA FERREIRANERY: UN HITO EN LA HISTORIADE LA \\ ENFERMERIA BRASILEÑA
}

\author{
Mania Manuela Vila Nova Cardoso \\ Cristina Maria Loyola Miranda²
}

\begin{abstract}
RESUMO: O objeto deste estudo é Anna Nery (1814-1880), uma mulher anônima, que participou da Guerra do Paraguai (1865-1870). Trata-se de um estudo biográfico de natureza sócio-histórica, que é orientado por principios da História Nova. O objetivo deste estudo é caracterizar a vida de Anna Nery. Alguns aspectos relevantes são levantados neste estudo. Anna Nery deixa o espaço privado do lar para assumir um papel importante no espaço público. A solicitaçāo de Anna Nery è puramente afetiva e não pediu para ser intitulada enfermeira. Anna Nery atendia às exigências que elevariam o status social e moral da enfermeira do século $X X$ e tornou-se simbolo da enfermagem brasileira
\end{abstract}

PALAVRAS CHAVE: Enfermagem, Historia, Biografia

\section{CONSIDERAÇÖESINICIAIS}

Embora muitas mulheres se tenham consagrado na história, adotando uma postura moldada nos deveres morais e civicos, por muitos anos as mulheres estiveram ausentes da historiografia oficial brasileira, e pouco se sabe de suas vidas, papéis e experiências no passado.

Uma das raras mulheres que mereceram menção na historiografia oficial, foi Anna Nery (1814-1880), uma mulher anônima, que ofereceu-se como voluntária para participar da Guerra do Paraguai (1865-1870), foi nomeada enfermeira e consagrou-se, sendo mencionada, de forma heróica como uma das mais ilustres mulheres da História do Brasil e da Enfermagem.

A biografia oficial de Anna Nery é sucinta. Autores como $D$. Ignez Sabbino (Mulheres Illustres do Brasil, 1899), Boccanera Júnior (As telas históricas do Paço Municipal da Bahia, 1922), Bernardino José de Sousa (Heroinas baianas, 1936), Edith Mendes da Gama e Abreu (Revista do Instituto Geográfico e Histórico da Bahia, 1967), restringem-se a repetir informações, limitando-se a uma reduzida exposição romanceada de episódios, que não nos satisfazem e instigam-nos a curiosidade e a vontade de desvendar o não-dito.

Não pretendemos realizar um estudo direcionado apenas a uma reconstituição histórica, mas a um conjunto de reflexões numa tentativa de reconstruir a sua memória e sua importância. Assim sendo, objetivamos, mediante a análise do contexto histórico, social, político, econômico e cultural, caracterizar a vida e o tempo de Anna Nery, procurando organizar uma parte da história não oficial, da história que não nos contaram ou que foi esquecida, que nos passou

\footnotetext{
' Professora Assistente do Departamento de Metodologia da Enfermagem - EEAN/UFRJ

2 Professora Titular do Departamento de Enfermagem Médico-Cirúrgica - EEAN/UFRJ.
} 
despercebida e que não despertou-nos o interesse em desvendá-la, contribuindo assim, para a memória da enfermagem brasileira.

\section{ABORDAGEM METODOLÓGICA}

Optamos por (re)construir uma existência pelo método qualitativo, descritivo, de natureza sócio-histórica, e por princípios orientados por uma corrente histórica que subverte o caminho tradicional da história - a História Nova.

Essa corrente conserva a proposta de uma ciência histórica que não mutile a vida das sociedades e que não eleve entre os diferentes pontos de vista sobre o devir dos homens as barreiras de subdisciplinas - história política, história diplomática, história militar, história econômica e, inclusive, história social ou história cultural (Le Goff, 1993, p.18).

Como fontes históricas utilizamos livros, manuscritos, folhetos, jornais, periódicos, dicionários, poemas, repertórios documentais e bibliográficos e obras gerais e específicas.

A escassez de dados exigiu uma viagem à cidade de Salvador-BA, entre 16 e 28 de julho de 1995, por um periodo de duas semanas, sendo realizada uma visita à Casa de Anna Nery, em Cachoeira.

Concluindo a coleta de dados dedicamo-nos à análise documental, com uma nova concepção de documento, acompanhada da critica. Não nos dispusemos a esperar que os fatos falassem por si, como em uma visão positivista da História. Interessou-nos interpretá-los e agrupá-los para confronto e análise, no intuito de construir um relato instigante e verdadeiro, ousando dar a nossa versão dos fatos, recusando sobretudo as certezas cômodas, e indo para além da mera exposição dos dados.

\section{ATRAJETÓRIA DE UMA MULHERANÔNIMA}

Anna Nery nasceu em 13 de dezembro de 1814, na Vila de Nossa Senhora do Rosário do Porto de Cachoeira, no prédio no 7 da antiga Rua da Matriz ${ }^{3}$, sendo batizada no dia 25 de março de 1815, na Igreja da Matriz, com o nome de Ana Justina Ferreira, pelo Padre Carlos Melequiades do Nascimento (Abreu, 1967, p.141).

Localizada ao lado da Igreja da Matriz, no centro de Cachoeira, em uma rua principal que inicia-se à direita da praça central, por onde partiam as ruas principais, a casa de Anna Nery, foi construída conforme o estilo de sua época. Em tamanho razoavelmente grande, comparada às da vizinhança, a casa tem dois andares. Pelo telhado possui eira, o que na época indicava um nivel social elevado de seus ex-residentes (Holanda, 1995, p.97).

Anna Nery pertencia a uma familia de patriotas legítimos, não havendo registros acerca da história de vida de seus pais: José Ferreira de Souza e Luiza Maria das Virgens. No entanto, seus quatro irmãos mereceram referências maiores na historiografia oficial, considerando a posição exercida na sociedade da época: Manoel Jeronymo Ferreira, Tenente-coronel que comandou o $10^{\circ}$ Batalhão de Voluntários da Pátria; Joaquim Mauricio Ferreira, Tenente-coronel que comandou $041^{\circ}$ Batalhão de Voluntários da Pátria; Ludgerio Rodrigues Ferreira, médico clinico de nomeada e de grande influência politica; e Antônio Benício Ferreira, conceituado corretor em Cachoeira (Boccanera Júnior, 1922, p.108; Abreu, 1967, p.141).

Nas camadas superiores da sociedade brasileira, as profissões masculinas eram indicadores da posição social. Os membros das mais prestigiosas profissões liberais, a medicina e o direito, poderiam ser considerados classe média alta. O homem definia o status da familia. A mulher era vista como apenas como uma criatura que Deus pusera no mundo com a única

\footnotetext{
${ }^{3}$ Hoje Rua Anna Nery pela Lei Municipal de 12 de agosto de 1926.
} 
finalidade de servir ao homem, ter filhos e prepará-los para a vida, garantindo o bom funcionamento do $\operatorname{lar}$ (BRAZIL, 1873-1876, p.21).

Educadas na clausura e confinamento do lar as meninas-moças, eram preparadas para o matrimônio e atingiam a flor-da-idade entre os 16 e 20 anos. A idade de 23 anos era considerada como limite das jovens casadoiras e foi nesse limite etário que Anna Nery casou-se, em 15 de maio de 1838, com o capitão-tenente da marinha Isidoro Antônio Néri, nascido em Lisboa, a 05 de setembro de 1800 .

Na condiçăo de mulher casada, Anna Nery devia seguir os modelos propostos pela Igreja brasileira, que tinha interesse em promover a mulher, acentuando seu papel de preciosa auxiliar, sendo impostas as mesmas obrigações transmitidas pelos manuais de conduta moral dos países católicos.

Ainda que tentando manter uma vida matrimonial nos moldes existentes, Anna Nery defrontou-se com periodos de ausência do esposo, que, engajado no serviço militar, era obrigado a dedicar-se ao oficio de capitão-de-fragata, navegando por toda a parte do território nacional. Vez por outra Isidoro retornava a Cachoeira onde permanecia por um curto período de tempo, suficiente doravante para que o casal desfrutasse do nascimento de três filhos: Justiniano de Castro Rebêllo (fevereiro de 18394); Isidoro Antônio Néri (24 de março de 1841); e Pedro Antônio Néri (13 de maio de 1842).

Casada, Anna Nery desempenhou o papel de esposa, ainda que por periodos curtos, e o de mãe, adotando a postura das mulheres na sociedade da época, seja na gerência do lar ou na educação dos filhos.

Em 05 de julho de 1844, Isidoro Antônio Néri faleceu, aos 43 anos de idade, acometido por súbita enfermidade, da qual não temos maiores registros. Viúva aos 29 anos de idade, com três filhos pequenos, o mais velho com cinco anos de idade. Anna Nery ganha então uma vida autônoma e independente, cheia de responsabilidades.

Apesar da aparência masculina da sociedade, em todas as camadas de Salvador era freqüente que a mulher assumisse sozinha o seu destino e o de seus filhos, desempenhando assim um papel importante, embora no espaço privado. A forma pela qual as mulheres poderiam "ter outra influência que não fosse sobre as panellas" ou "outra missão além das costuras" era através da "educação de seus filhos", pois estes aprendiam com sua mãe as primeiras lições e os princípios morais. Esta tarefa nobre de educar os filhos valorizou as mulheres. Além do mais, uma forma de modificar a mente dos homens era moldando a dos meninos (JORNAL DAS SENHORAS 5 , 01/01/1852, p.6).

Nesse sentido, Anna Nery mudou-se para Salvador supõe-se "quando os filhos terminaram a instrução secundária", de modo a garantir-Ihes estudos e conseqüente ascensão social, permanecendo no anonimato até a sua inserção no contexto da Guerra do Paraguai, quando inicia o caminho de consagração nacional.

\section{A HEROINA DA GUERRA}

Viúva desde 1844, Anna Nery, mantinha-se no espaço privado do lar, desenvolvendo atividades do cotidiano da mulher daquela época.

No quadro de viúvas, projetava-se a idéia geral de uma posição de autonomia na família. Caracterizavam-se por uma vida independente e, na maioria das vezes, na liderança de um

\footnotetext{
${ }^{4}$ Näo há registros do dia do nascimento. Por curiosidade, é o único filho que năo recebe o sobrenome dos pais.

${ }^{5}$ O Jornal das Senhoras tentou utilizar o papel da mulher como mãe de modo a elevar sua posiçăo.
}

R. Bras. Enferm., Brasilia, v. 52, n. 3, p. 339-348, jul./set. 1999 
grupo familiar.

A viúva devia viver como as mulheres virgens, ser vigilante com as mulheres casadas e dar exemplos virtuosos a umas e outras, sendo amiga dos retiros e inimiga dos divertimentos mundanos. Aplicada na oração, devia zelar cuidadosamente pela sua boa reputação, amar a mortificação e trabalhar para a glória de Deus, ou seja, sustentar-se em obrigações impostas pela influência da Igreja (Mattoso, 1992, p.411).

Nos meados do século XIX, Anna Nery vivia com dois de seus filhos na cidade de Salvador para onde mudou-se, supõe-se que motivada pela necessidade de fornecer-lhes melhor instrução ou mesmo se considerarmos o fato de um de seus filhos já se encontrar na capital, inserido à vida universitária, instigando a vontade de seus irmãos aos estudos e a responsabilidade da mãe em acompanhá-los.

Engajados em estabelecimentos de ensino superior, todos os filhos de Anna Nery seguiram o serviço militar. Justiniano de Castro Rebêllo e Isidoro Antônio Néri dedicaram-se à medicina, enquanto que o filho mais novo, Pedro Antônio Néri, dedicou-se à carreira militar, era cadete aluno da Escola Militar do Rio de Janeiro.

Com a entrada do Brasil na Triplice Aliança, juntamente com o Uruguai e a Argentina em 1865, Anna Nery, aos 51 anos, viu seus filhos partirem para a guerra contra o Paraguai e, em uma carta destinada ao Presidente da Província da Bahia, Manuel Pinto de Souza Dantas, datada de 08 de agosto de 1865, ofereceu-se para servir aos feridos de guerra.

"IIIm. Exm. Sr.:

- Tendo já marchado para o exercito dois de meus filhos, alêm de um irmão e outros parêntes, e havendo se offerecido o que me restava nesta cidade, alluno do 6 ㅇ anno de Medicina, para também seguir a sórte de seus irmãos e parêntes, na defesa do pais, offerecendo seus serviços médicos, - como brasileira, não podendo ser indifferênte aos sofrimêntos dos meus compatriótas, e, como mãe, não podendo resistir à separação dos objectos que me são caros, e por uma tão longa distância, desejava acompanhal-os por toda a parte, mesmo no theatro da guerra, si isso me fôsse permittido; mas oppondo-se a este meu desejo a minha posição e o meu séxo, não impédem, todavia, estes dois motivos, que eu offereça os meus serviços em qualquer dos hospitais do Rio Grande do Sul, onde se façam precisos, com o que satisfarei ao mêsmo tempo os impulsos de mãe, e os deveres da humanidade para com aquelles que óra sacrificam suas vidas pela honra e brio naciónais e intégridade do Império. Digne-se V. Ex. de acolher benigno este meu espontâneo offerecimênto, ditádo tão sómente pela vóz do coração.

- Bahia, 8 de agôsto de 1865. Deus Guarde a V. Ex. - Illm e Exm. Sr. Dr. Manuel Pinto de Souza Dantas - Mui digno Presidente desta provincia.

- D. Ana Justina Ferreira Néri" (DIÁRIO DA BAHIA, 11 de agosto de 1865).

Muito embora o patriotismo sobressaia nas entrelinhas do discurso, Anna Nery desde 0 inicio menciona o desgosto resultante do afastamento de seus familiares. Como mãe não resistiria à separação de seus filhos. Esta expressão parece-nos romântica e decisiva no que diz respeito à comoção dos leitores, dando-nos a idéia de apelaçăo aos mais profundos deveres de maternidade. Viúva e afastada de seus filhos, Anna Nery mobilizou-se para não perdê-los, e sua atitude repercutiu na superação da imagem social da mulher na época, na medida em que desempenhou muito mais do que exigiam os papéis vigentes de mãe e de mulher.

Quanto aos dois motivos que Anna Nery relata oporem-se ao seu desejo: a sua posição e o seu sexo, supostamente Anna Nery deixa nas entrelinhas o fato de pertencer à camada social privilegiada, onde nas mulheres estranhava-se a vontade e a disposição para enfrentar o duro ofício de um sacrifício tão grande, tal qual o de Anna Nery.

Por último, quando Anna Nery se oferece para atuar em hospitais do Rio Grande do Sul,

\footnotetext{
${ }^{6}$ O mais novo encontrava-se no Rio de Janeiro cursando a carreira militar.
} 
surgem dúvidas quanto a experiências que Anna Nery pudesse ter no oficio da enfermagem. Sabe-se contudo, que nos meados do século XIX, são fundadas em Salvador associações de caridade. A exemplo, a Sociedade das Damas de Caridade reunia mulheres de camadas elevadas da sociedade local, já que seus membros eram recrutados entre ricos proprietários de terra, grandes comerciantes, profissionais liberais e altos funcionários. Essas mulheres eram preciosas auxiliares das Irmãs de São Vicente de Paulo, que dirigiam a maior parte das obras caridosas femininas da cidade. Além de visitar os pobres e cuidarem dos doentes a domicílio, as Irmãs de São Vicente de Paulo fundavam colégios e casas admitindo alunas internas e externas, muitas delas órfãs (Mattoso, 1992, p.386 e 413).

Se Anna Nery teria pertencido à Sociedade das Damas de Caridade, não poderemos responder se considerarmos a ausência de registros, porém é interessante mencionar que Anna Nery foi também cognominada "a grande irmã de caridade leiga".

A resposta do Presidente da Provincia da Bahia ao apelo de Anna Nery foi breve, sendo expedidas ordens ao Conselheiro Comandante das Armas para que Anna Nery fosse contratada como primeira enfermeira.

"O rasgo do patriótismo e de abnégação com que V.M., depois de ter visto seguir para o campo de guerra, em que se acha empenhado o pais, um irmão e dois filhos, e agóra o terceiro, como médico, se offeréce para, acompanhando-os em tão nóbre missão, prestar os serviços de humanidáde compativeis com o seu séxo e idade, nos hospitais do Rio Grande do Sul, não póde deixar de ser benevolente acolhido por esta Presidência, que folga de louvar os sentimêntos com que V.M., por êsse àcto tão importante e digno de inveja, se torna recommendável ao pais. Aceito, pois, tão espontâneo offerecimento, e vão ser expedidas órdens ao Conselheiro Commandante das Armas, com quem se entenderá V.M. para ser contractada como primeira enfermeira ${ }^{7}$, e brévemente seguir para o Rio de Janeiro." (DIÁRIO DA BAHIA, 13 de agosto de 1865).

Cinco dias depois, no dia 13 de agosto de 1865, embarcou Anna Nery para os campos de batalha, onde sua atuação parece ter sido primorosa, porém surpreendeu-nos a quase total ausência de registros fundamentados sobre a sua participação.

Em sua passagem pelo Rio Grande do Sul, Anna Nery teria tomado lições de enfermagem com as Imãs da Caridade de São Vicente de Paulo, assim como havia desenvolvido um curto estágio em Salto (Argentina), onde estabeleceram-se grandes depósitos e hospitais de sangue, onde os feridos dos últimos combates convalesciam de suas enfermidades (Lima, 1977, p.132).

O título "Mãe dos Brasileiros" foi-lhe conferido pelos obreiros da glória (soldados), segundo a obra de Rozendo Muniz Barreto ${ }^{8}$, o Poemeto Histórico "A Mãe dos Brasileiros". Nesta obra única, de vinte e duas páginas manuscritas, o autor em versos, afirma com convicção a caridade de Anna Nery, tendo sido testemunho do auxilio que esta prestava aos enfermos.

Quando eu a tão justo espanto, não sabia achar um termo,

- "D'Ana ..." chamou-a enfermo, cuja voz chamou meu pranto.

Pressurosa ella acudiu-Ihe, ancias da sêde extinguiu-lhe e as feridas Ihe pensou, depois disse: "Está me entregue... cumpra o que ordeno... socegue na esperança que lhe dou"

E renovando confortos nos leitos que visitava, essa heroina avivava os prostrados semimortos.

\footnotetext{
${ }^{7}$ Chama-nos à atençăo com que rapidez Anna Nery ganhou a função de enfermeira.

${ }^{8}$ Baiano, estudante do $4^{\circ}$ ano de medicina, voluntário a servir nos hospitais de sangue de 1866 ao fim da guerra.
} 
E ao vel-a em torno dos doentes, alegrando os descontentes como as aves a manhan, diziam da glória obreiros -"Ella é mãe dos Brasileiros, da caridade é a irman"

(Barreto, s.d., p.11)

Alguns autores ainda afirmam o fato de Anna Nery ter fundado e mantido uma enfermaria em sua residência em Assunção.

"E onde havia auxilio igual, se ela fez, por duplo auxilio:

- hospital - seu domicílio,

-seu domicilio - o hospital ?"

(Barreto, s.d., p.11)

Não bastasse a dor e morte de alguns enfermos que atendia, Anna Nery teve ainda que enfrentar a morte do filho mais velho, Justiniano de Castro Rebêllo e a do sobrinho Arthur Rodrigues Ferreira.

Dentre as homenagem recebidas em campos de batalha, podemos citar o Diploma de Sócia Honorária da Sociedade de Socorros em Corrientes e o de Sócia Instaladora da Sociedade de Beneficência Portuguesa em Assunção (Silva, 1942, p.14).

Findada a Guerra em 1870, Anna Nery inicia o retorno ao Brasil, trazendo consigo seis órfãs ${ }^{9}$, conforme refere $D$. Ignez Sabbino $(1899$, p.24), que afirma ter visto uma foto, tirada em Montevidéu. Essa foto foi encontrada nos acervos fotográficos do Centro de Documentação da Escola de Enfermagem Anna Nery. Trata-se de uma reprodução de retrato encontrado entre os documentos pessoais de Benjamin Constant ${ }^{10}$.

Apesar de outras mulheres terem atuado como enfermeiras voluntárias da Guerra do Paraguai, apenas Anna Justina Ferreira Nery, "envolvida pela aura do patriotismo, recebeu reconhecimento. Mas não a maioria das mulheres que ganhava a vida às custas de seu trabalho de enfermagem. Suas vidas de renúncia não eram uma escolha voluntária (...)" (Hahner, 1981, p.73).

\section{GLORIFICAÇÃOE MORTE DA HEROINA}

Anna Nery chega ao Rio de Janeiro em 06 de maio de 1870, sendo recebida por senhoras baianas ali residentes, as quais concederam-lhe um Álbum guamecido de madrepérola e prata, tendo sobre a parte superior suas iniciais, AJFN, no interior a seguinte dedicatória: Tributo de admiração à caridosa baiana por alguns compatriotas.

Os seus conterrâneos residentes na Côrte, mandaram tirar seu retrato em tamanho natural, para ser oferecido à Província da Bahia. Trata-se de uma tela em que Victor Meirelles representou Anna Nery de pé e, ao fundo, o espaço público ocupado, um campo de batalha

\footnotetext{
${ }^{9}$ Alguns fatos que instigam esclarecimentos ainda năo desvendados: O que faziam crianças em campos de batalha? Como se deu o encontro de Anna Nery com tais órfăs?

${ }^{10}$ Doada à Escola de Enfermagem Anna Nery pelo Museu Benjamin Constant em 1981.

"É interessante ressaltar que essa corôa somente encontra referência quando de sua chegada a Salvador, porém, na passagem pelo Rio de Janeiro, quando a obra foi elaborada, ela já aparece sustentada em Anna Nery.
} 
fictício. Na cabeça uma corôa de louros ${ }^{11}$. No rosto, as marcas do cansaço e da tristeza. No corpo, a roupa preta, com uma medalha afixada à direita do peito.

O Governo Imperial concedeu-lhe ainda, pelo decreto datado de 18 de maio de 1870 , a Medalha de $2^{2}$ classe, a Medalha de Campanha, com passador de ouro $n \circ 5$ e uma pensão anual de um conto e duzentos mil réis.

Deixando o Rio de Janeiro, Anna Nery retornou à província Natal, chegando à Bahia em 05 de junho de 1870 , à bordo do vaporArinos.

Na noite de 06 de junho, um dia após a sua chegada, senhoras das mais ilustres famílias baianas, precedidas da philarmônica Minérva e da música do Corpo da Polícia, foram felicitar Anna Nery em sua casa de residência ${ }^{12}$, brindando-a com uma riquissima Corôa de Louros ${ }^{13}$, cravejada de brilhantes (Boccanera Júnior, 1922, p.112).

Três anos após o regresso de Anna Nery, chega à Bahia a tela a óleo de Victor Meirelles, à qual já nos referimos, que foi solenemente colocada no Salão das Sessões do Paço Municipal de Salvador, a 28 de setembro de 1873, onde se encontra até hoje.

Por alguns anos cessaram os atos de exaltação e louvor a Anna Nery, que nesse recorte temporal mudou-se para o Rio de Janeiro' ${ }^{14}$, para onde seu filho Pedro Antônio Néri, então Capitão do Exército, foi mandado para prestar serviços.

No Rio de Janeiro, em uma confortável casa assobradada, situada à Rua Senador Eusébio, no 290, Flamengo, Anna Nery viveu os últimos anos de sua vida. Adoeceu gravemente em princípios de 1880 , falecendo às $16: 30$ horas do dia 20 de maio do mesmo ano, aos 65 anos de idade (Ipanema, 1980, p.9).

Anna Nery foi sepultada às 17:00 do dia seguinte, no Cemitério São Francisco Xavier, em jazigo perpétuo, sendo exaltada à beira do túmulo, que na lápide continha a seguinte inscrição: Aqui descansam os restos mortais de Da. Ana Néri, denominada Mãe dos Brasileiros, pelo Exército, na campanha do Paraguai.

O tempo não apagou da memória dos brasileiros o nome de Anna Nery e por muitos anos foram-Ihe prestadas diversas homenagens.

No Rio de Janeiro, em 31 de março de 1926, pelo Decreto № 17.268, o governo deu a denominação de Ana Néri à Escola de Enfermeiras do Departamento Nacional de Saúde Pública, que passou a pertencer à Universidade do Brasil ${ }^{15}$, como ensino superior, desde o Decreto $\mathrm{n} 0$ 8.393, de 17 de dezembro de 1945.

Em 1ㅇ de fevereiro de 1979, no Rio de Janeiro, uma Comissão formada por Pedro Calmon ${ }^{16}$, pelo Ministro José Moreira Rabelo e pela Diretora da Escola de Enfermagem Anna Nery, Cecília Pecego Coelho, reuniu-se no Cemitério São Francisco Xavier para exumação dos restos mortais de Anna Nery (Coelho, 1979, p.1).

Os despojos foram colocados em uma urna de jacarandá e prata, oferecida pela Universidade Federal da Bahia, que foi encaminhada ao Pavilhão de Aulas da Escola de Enfermagem Anna Nery, onde permaneceu em exposição até às 6:30 horas do dia 4 de fevereiro, quando foi levada ao aeroporto Santos Dumont e entregue ao Setor da Aeronáutica Militar para o transporte à Bahia e posteriormente à cidade de Cachoeira.

Após o fim das cerimônias do translado em Cachoeira, a urna foi levada à sacristia da Igreja da Matriz, onde ficaria até a sua deposição no centro da nave principal da mesma. Uma

\footnotetext{
${ }^{12}$ Não há registros referentes ao endereço de Anna Nery em Salvador.

${ }^{13}$ Corôa de folhetos de ouro $18 \mathrm{~K}$, mede $35 \mathrm{~cm}$ de diâmetro, rematada por larga fita de gorgulhäo. onde ainda se lê: "Ả Heroina da Caridade, as baianas reconhecidas". (Silva, 1942, p.18)

${ }^{14}$ Não foram encontrados dados referentes à data em que Anna Nery deixa Salvador e mudase para o Rio de Janeiro.

15 Hoje Universidade Federal do Rio de Janeiro.

${ }^{16}$ Ex-reitor da Universidade Federal do Rio de Janeiro.
} 
das últimas homenagens de que temos noticia.

CONSIDERAÇÕES FINAIS

É relevante a contribuição de Anna Nery à nossa profissão, considerando sua bondade, caridade, altruísmo, desprendimento, dedicaçăo, humanidade, amor ao próximo, dentre outros, porém alguns aspectos analisados no decorrer deste estudo devem ser considerados.

Anna Nery pertencia à classe média alta da sociedade. Era irmã, esposa e mãe de militares, alguns dos quais engajados em profissões liberais como a medicina, que compunham os heterogêneos setores médios brasileiros.

As mulheres de camadas elevadas da sociedade baiana, sustentavam-se em obrigações impostas pela influência da Igreja. Comumente essas mulheres associavam-se a irmandades e ordens religiosas para desenvolver a caridade.

Quanto à solicitação de Anna Nery para participar da guerra, por mais que evoque o patriotismo, seu apelo é puramente afetivo e pessoal. Toma-se dificil acreditar que uma mulher viúva, após vinte e um anos de dedicação solitária ao cuidado dos filhos, diante da ameaça de perdê-los durante a guerra, tenha feito solicitação para acompanhá-los por razões patrióticas.

Anna Nery, ao oferecer seus serviços a hospitais do Rio Grande do Sul, não previa que as circunstâncias levassem-na para além dos limites do solo brasileiro, porém, não se indispôs ou rebelou-se com estas circunstâncias, prosseguiu e alcançou a glorificação.

Foi nomeada primeira enfermeira, mas não solicitou para receber esse título ou engajarse nessa profissão. Devemos considerar também, que no século XIX a reforma Nightingale estava iniciando o seu curso na Inglaterra, portanto, é absolutamente esperado que no Brasil chamassem de enfermeiras todas as mulheres que se dedicassem ao cuidado a doentes.

Com relação à Guerra do Paraguai, por tratar-se de um massacre, seria interessante desconfiar, por um lado, da divulgaçăo do pedido de Anna Nery para participar dessa guerra, o que causou grande repercussão social, e por outro, da rapidez e da pressa com que este foi aceito e ela foi nomeada enfermeira. Tais fatos favoreceriam politicamente a imagem da guerra, no que conceme a estender à população as intenções patrióticas e voluntárias dos que ofereciam para atuar na guerra, aliviando a situação dos alistados involuntariamente. Por outro lado, em uma guerra cruenta, ter uma Mãe enfermeira, melhora muito a situação do Brasil, em termos de simpatia e aceitação popular.

Quando da morte de seu filho, Anna Nery poderia ter voltado e não o fez. Qual mãe não voltaria? Anna Nery continuou lá, transformou sua casa em um hospital, adotou órfãs e trouxeas consigo. O papel de mãe associa-se ao daquela que cuida, o de enfermeira.

Dentre tantas homenagens, curiosas são aquelas prestadas de imediato a sua chegada ao Rio de Janeiro e a Salvador, como que seu bom desempenho na guerra tivesse alcançado também o território brasileiro, onde era esperada com um pacote pronto de homenagens.

Por fim, deverá considerar-se a necessidade de elevar o status social e moral da enfermeira do século XX, tão degradados nos séculos anteriores. Haveria de se encontrar, dentre tantas enfermeiras, aquela que pudesse identificar profissionalmente a enfermeira, que se destacasse socialmente, que possuísse boas condições sócio-econômicas, que detivesse uma formação moral e mantivesse um comportamento disciplinado.

Anna Nery atenderia a todos as exigências, e tomou-se símbolo da enfermagem brasileira. 
ABSTRACT: The object of this study is Anna Nery (1814-1880), an anonymous woman who participated in the Paraguay War (1865-1870). This is a social-historical biographical study guided by the principles of the New History. The objective of this research is to characterize and raise relevant aspects of Anna Neri's life. It is known that this woman left her domestic life to play an important role in the public space. Her motivation was genuinely affectionate, and she didn't expect to be called a nurse. Anna Neri met the requirements that would raise the social and moral status of the $X X$ th century nursing workers, and became a symbol of Brazilian nursing

KEY WORDS: nursing, history, biography

RESUMEN: El objeto de este estudio es Anna Nery (1814-1880), una mujer anónima que participó en la Guerra del Paraguay (1865-1870). Es un estudio biográfico de naturaleza histórico-social que está orientado por los principios de la Nueva Historia. Su objetivo es caracterizar la vida de Anna Nery. Algunos aspectos relevantes se destacan. Anna Nery sale del espacio privado del hogar para asumir un papel importante en el espacio público. El móvil de Anna Nery fue puramente afectivo y ella no pidió que le dieran el título de enfermera. Anna Nery atendia, asi, a las exigencias que elevarian el status social y moral de la enfermeria, del siglo $X X$ y pasó a ser el simbolo de la enfermeria brasileña.

PALABRAS CLAVES: Enfermeria, Historia, biografia

\section{BIBLIOGRAFIA}

ABREU, Edith Mendes da Gama e. Anna Nery. Rev. Inst. Geog. Hist. da Bahia. Bahia: IGHB, v. 83, p. $140-145,1961-1967$

BARRETO, Rozendo Muniz. A Mãe dos Brasileiros. Poemeto Histórico oferecido ao Inst. Hist. e Geográfico Brasileiro em 1876. s. d., (manuscrito)

BOCCANERA JÚNIOR. As telas históricas do Paço Municipal da Bahia: biographias e notícia histórica do Paço. Bahia: Typ Commercio, 1922.

BRAZIL. Diretoria Geral de Estatistica. Recenseamento da populaçăo do Império do Brasil. 12 de agosto de 1872. Rio de Janeiro: Typ - Leuzinger, 1873-1876.

COELHO, Cecilia Pecego. Ata da Homenagem a Anna Nery - Mãe dos Brasileiros por ocasião de translaçāo de seus restos mortais do Rio de Janeiro para a sua terra natal. Rio de Janeiro, 1979. (mimeogr.)

DIÁRIO DA BAHIA, Salvador, 11 de agosto de 1865

DIÁRIO DA BAHIA, Salvador, 13 de agosto de 1865.

HAHNER, June E. A mulher brasileira e suas lutas sociais e politicas: 1850-1937. São Paulo: Brasiliense, 1981.

HOLANDA, Sérgio Buarque de. Raízes do Brasil. 26. ed. São Paulo: Companhia das Letras, 1995. 
IPANEMA, Cybelle. No centenário de morte de $D$. Ana Justina Ferreira Néri. Comunicação lida na Comissão de Estudos e Pesquisas Históricas em reuniăo realizada a 21 de maio de 1980. (mimeogr.)

LE GOFF, Jacques. A História Nova. São Paulo: Martins Fontes, 1993.

LIMA, Joăo Francisco de Lima. Ana Néri: heroina da caridade, patrona das enfermeiras. Săo Paulo: Nova Época Editorial, 1977.

MATTOSO, Katia M. de Queirós. Bahia, Século XIX - uma província no Império. Rio de Janeiro: Nova Fronteira, 1992.

O JORNAL DAS SENHORAS, Salvador, $1^{\circ}$ de janeiro de 1852.

SABBINO, D. Ignez. Mulheres illustres do Brasil. Rio de Janeiro: Garnier, 1899.

SILVA, Maria Leonor Alvares. Galleria: o livro das biografias. São Paulo: Biblos, 1954.

SILVA, Pedro Celestino da. Anna Nery. Rev. Instit. Geog. e Histórico da Bahia. Bahia: IGHBA, 68, p. 11-23, 1942.

SOUSA, Bernardino José de. Heroinas baianas: Joana Angélica, Maria Quitéria e Anna Nery. São Paulo: Paralelo/MEC, 1936. 